\title{
Synthesis of Sulfur-Rich Polymers: Copolymerization of Cyclohexene Sulfide and Carbon Disulfide using Chromium Complexes.
}

Selena Silvano, Chiara Francesca Carrozza, Alberto de Angelis, Incoronata Tritto, Laura Boggioni,* and Simona Losio* 


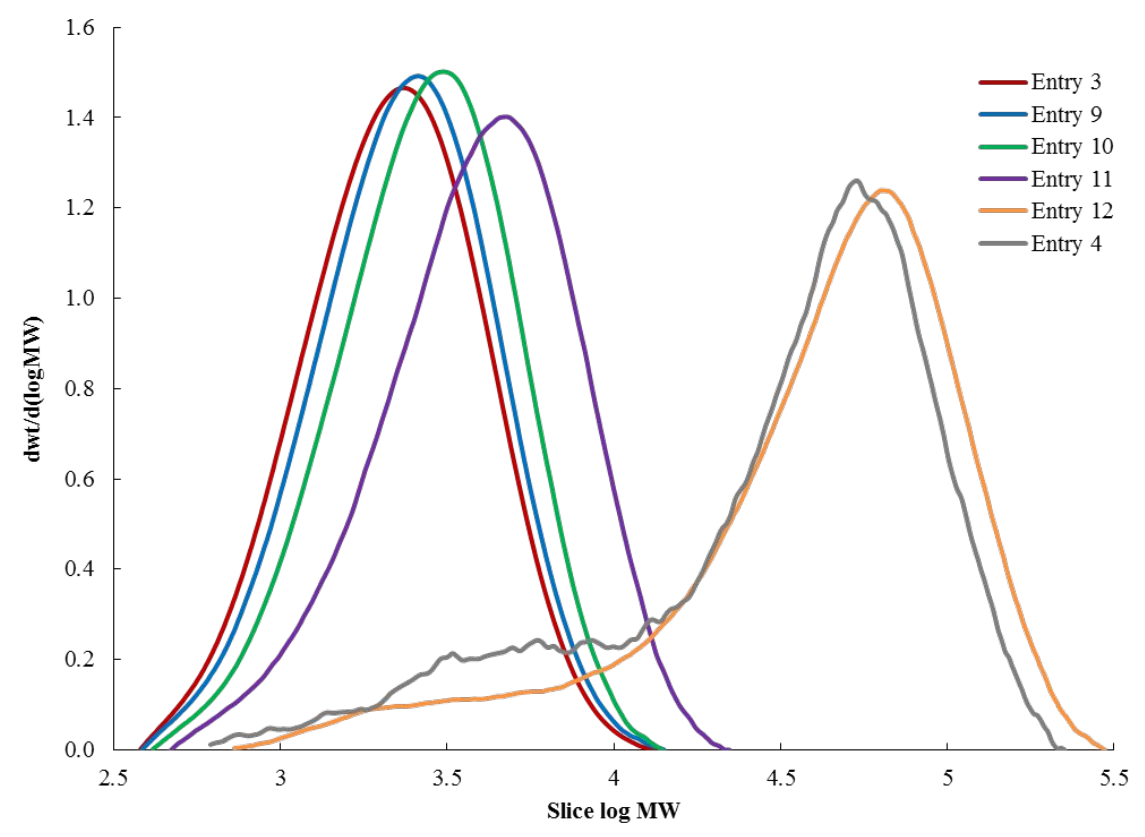

Figure 1S. SEC curves of the reaction carried out with catalyst $\mathbf{1}$ and $[\mathrm{PPN}] \mathrm{N}_{3}$ at different reaction time. 


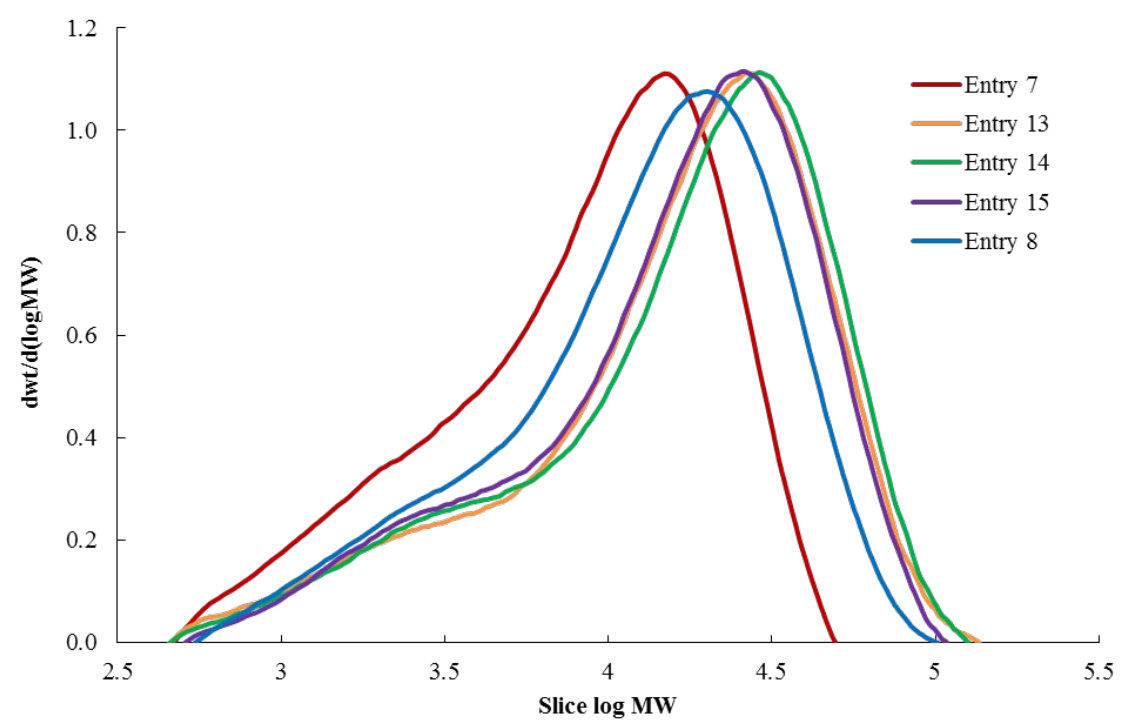

Figure 2S. SEC curves of the reaction carried out with catalyst 3 and $[\mathrm{PPN}] \mathrm{N}_{3}$ at different reaction time. 


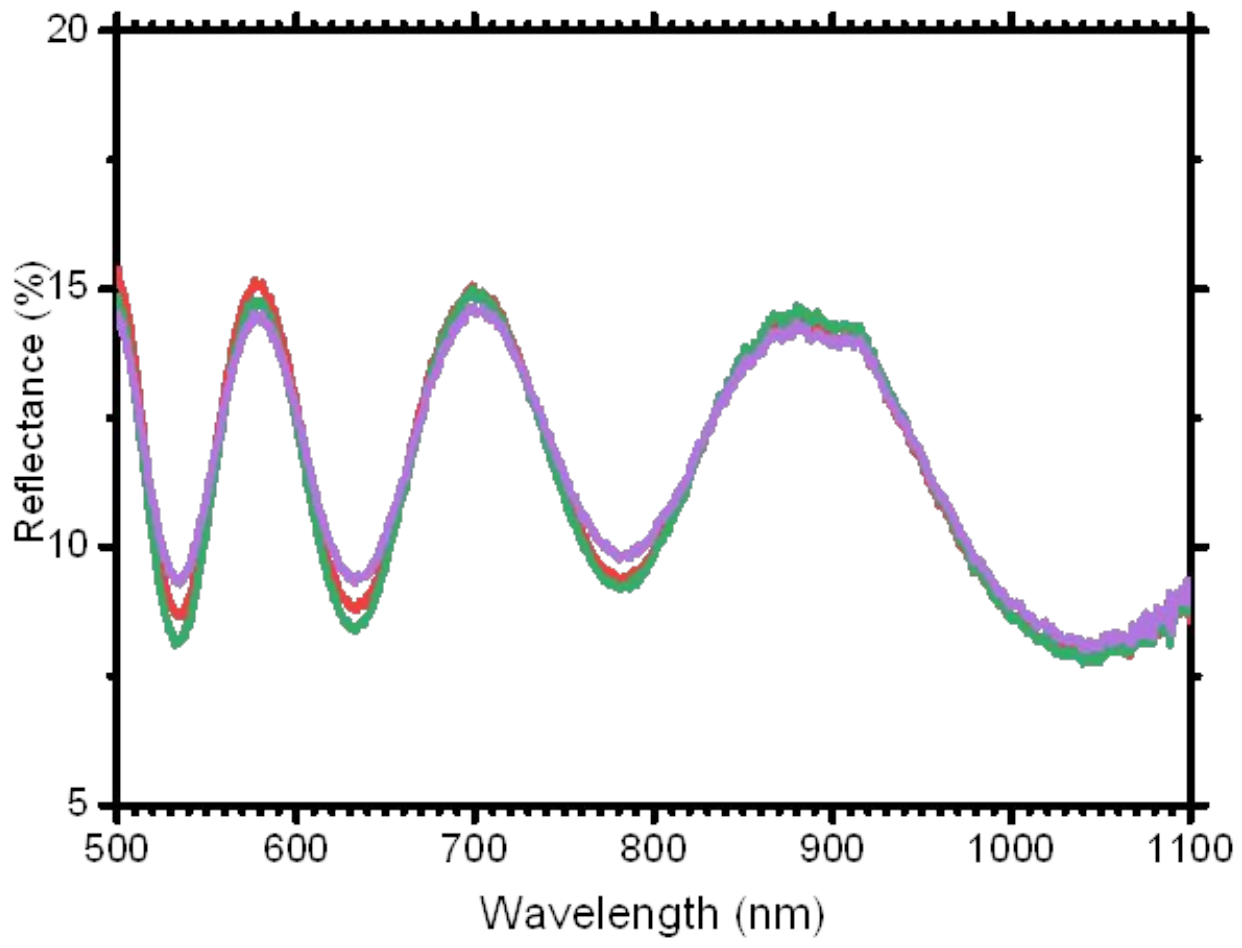

Figure 3S. Reflectance (\%) trend as a function of wavelengh for entry 12. 
A

E. Coli
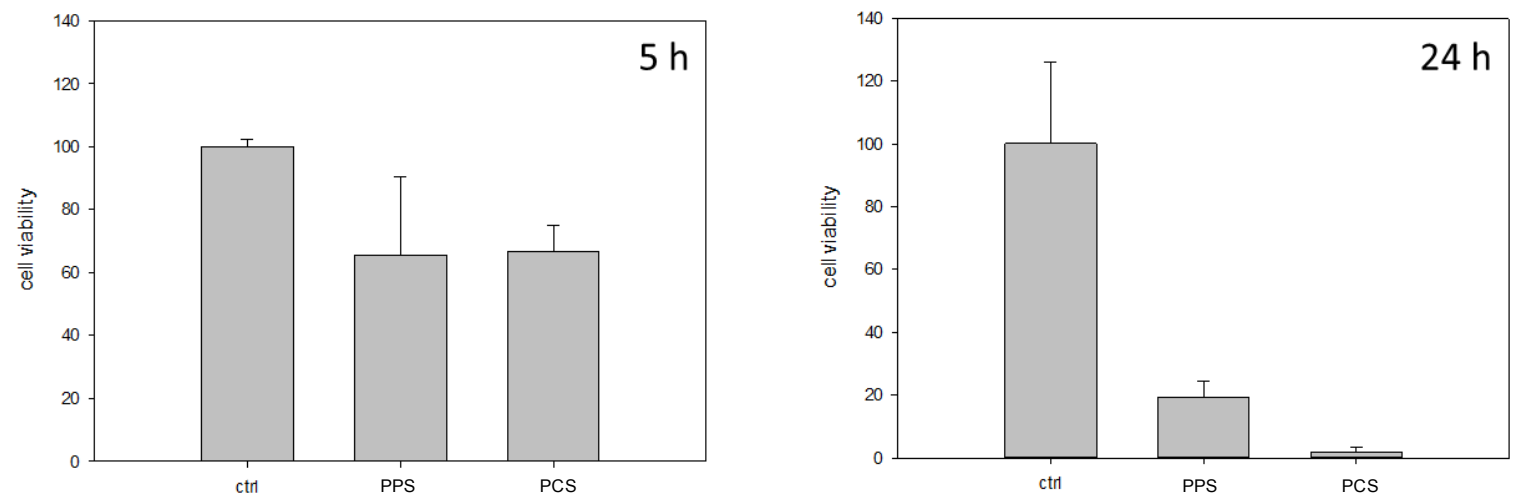

B

S. Aureus
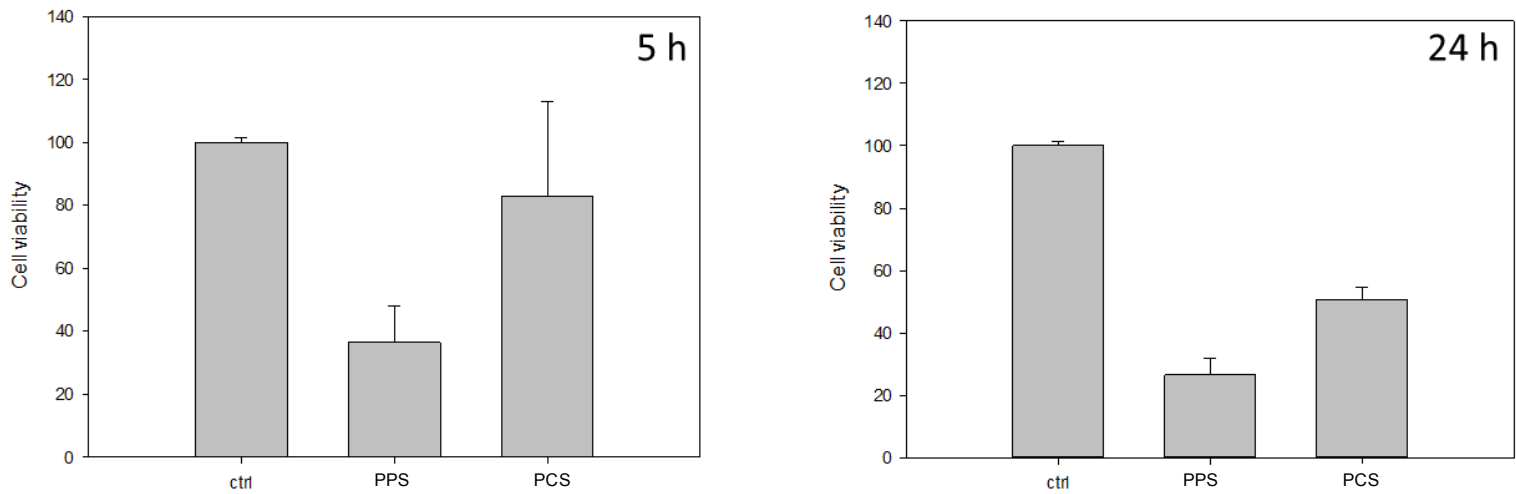

Figure 4S. Cell viability, calculated by counting surviving colonies, at different contact time 5 and 24 hours for $E$. Coli (Panel A) and for S. Aureus (Panel B). Error bars represent the standard deviations from three independent replicates 